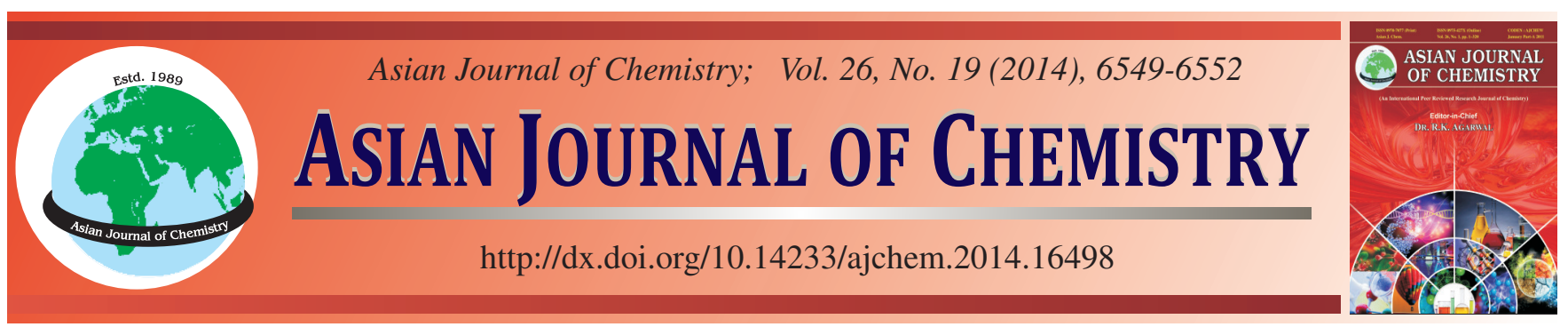

\title{
Optimization of Ultrasonic- and Microwave-Assisted Extraction of Antibacterial Compounds from Amomum tsao-ko Fruit
}

\author{
Meifang Peng, Houyuan Qiu, Wenxue Chen* and Dan Wang
}

College of Food Science and Engineering, Haikou 570228, Hainan Province, P.R. China

*Corresponding author: Fax: +86 898 66193581; Tel: +86 13976121821; E-mail: hnchwx@163.com

\begin{abstract}
The extraction of antibacterial compounds from Amomum tsao-ko fruit was optimized for ultrasonic- and microwave-assisted methods. The antibacterial activity of the extracted compounds was determined based on the antibacterial diameter. To optimize the extraction procedure, the ethanol concentration, solvent-to-solid ratio, extraction temperature, and extraction time were evaluated using single factor experiments and the response surface methodology. A Box-Behnken design and analysis of variance were used to determine the optimal extraction conditions from the experimental data. The optimal parameters included an ethanol concentration of $65 \%$ (v/v), a solvent-tosolid ratio of $25 \mathrm{~mL} / \mathrm{g}$, an extraction temperature of $57.5^{\circ} \mathrm{C}$ and an extraction time of $52.5 \mathrm{~min}$. The extract obtained under optimized conditions had a maximum antibacterial diameter of $14.20 \mathrm{~mm}$ for Escherichia coli.
\end{abstract}

Keywords: Amomum tsao-ko, Antibacterial diameter, Box-Behnken design, Response surface methodology.

\section{INTRODUCTION}

Amomum tsao-ko Crevost et Lemaire (Zingiberaceae) is widely distributed in Southwest China. Its dried fruit is usually used as a form of traditional Chinese medicine for malaria, throat infections, abdominal pain, stomach disorders, dyspepsia, nausea, vomiting and diarrhea. Amomum tsao-ko is commercially important in the Southeast Asian market as a spice that provides a distinct flavor.

Previous studies have demonstrated the biological and pharmacological activities of Amomum tsao-ko' ${ }^{1}$. Several components and bioactive substances from this plant have already been reported, including the antifungal bicyclic nonanesisotsaokoin, its isomer tsaokoin, the antioxidant catechins, the antiproli-ferative bicyclononane aldehydes and the cytotoxic tsaokoaryloneall ${ }^{2-5}$. The essential oil from Amomum tsao-ko is cytotoxic to HepG2, Hela, Bel-7402, SGC7901 and PC-3 cell lines, as well as induces apoptosis in HepG2 cells $^{6}$. Moreover, its methanol extract attenuated nitric oxide production in lipopolysaccharide-simulated BV2 microglia, whereas its ethyl acetate extract produced an oral trigeminal effect $^{7,8}$. The fat-soluble polar components of Amomum tsaoko contain an active component associated with decreased plasma glucose and thiobarbituric acid reactive substances (TBARS) concentrations in mice ${ }^{9}$. The ethanolic extract of Amomum tsao-ko had high antibacterial activity for Staphylococcus aureus and Escherichia coli ${ }^{10}$.
Natural antibacterial extracts, particularly those from edible plants, have received much interest, as evidenced by the escalating amount of published research. Common extraction methods include maceration, Soxhlet extraction, ultrasound-assisted extraction (UAE) and microwave-assisted extraction (MAE) $)^{11-16}$. Interest in the applications of ultrasound and microwave radiation to natural product extraction has increased because of their advantages, including the reduced extraction time, lower energy requirement and increased yield. Thus, the combined ultrasonic- and microwave-assisted extraction (UMAE) foreseen as a potentially more attractive extraction method $^{17,18}$.

The response surface methodology (RSM) is a collection of statistical and mathematical techniques for developing, improving and optimizing processes. Response surface methodology was first developed in 1951 by Box and Wilson. This methodology has been used to optimize the extraction processes of antibacterial compounds from various plant materials based on several conventional and novel techniques ${ }^{12,13}$.

This study aimed to optimize the extraction procedure for antibacterial compounds from Amomum tsao-ko fruit using RSM by ultrasonic- and microwave-assisted extraction.

\section{EXPERIMENTAL}

Dried Amomum tsao-ko fruit was purchased from the Wangjiawang supermarket in Haikou on June 2012. The samples were ground into particles small enough to pass 
through a 40-mesh sieve. The test bacterial species, Escherichia coli, was supplied by the Food College of Hainan University.

Analytical grade ethanol was purchased from the Bai Sha Male Ocean Industrial Co., Ltd. (Guangzhou, China). Water was purified using an WP-UP-UV-10 ultrapure water machine (Sichuan Wo Te Er Science and Technology Development Co., Ltd., Sichuan, China).

A CW-2000 UMAE system (Xintuo Microwave Sample Dissolution Testing Technology Co., Ltd., Shanghai, China) was used for sample extraction. A RE52-99 rotary evaporator (Shanghai Yarong Biochemistry Instrument Factory, Shanghai, China) was used to concentrate the samples.

Extraction of antibacterial compounds: The following extraction procedure was performed: The Amomum tsao-ko fruit powder was soaked for $20 \mathrm{~h}$ in the extraction solvent. Subsequently, UMAE extraction was performed. The obtained extract was filtered, concentrated and dried. After cooling, the extract was stored at $4{ }^{\circ} \mathrm{C}$ until further use.

Experimental design: To optimize the extraction process, a single-factor experiment was applied to determine the proper range for each factor. RSM was used to analyze the interactions between the different extraction parameters. A Box-Behnken design was used to assess the optimal extraction conditions.

Determination of antibacterial activity: The perforated diffusion method was used to measure the degree of antibacterial activity ${ }^{19}$. Initially, $18 \mathrm{~mL}$ of the nutrient agar was added to each petri dish. After cooling the medium, $0.1 \mathrm{~mL}$ of the E. coli suspension $\left(10^{7}\right.$ to $\left.10^{8} \mathrm{cfu} / \mathrm{mL}\right)$ was added and evenly distributed on the plate. Four equidistant perforations $(6 \mathrm{~mm})$ were then made on the agar plates and $0.05 \mathrm{~mL}$ of the Amomum tsao-ko extract $(0.1 \mathrm{~g} / \mathrm{mL})$ was injected into each hole. The corresponding dissolution solvent was used as the control treatment. The cultures were incubated at $37^{\circ} \mathrm{C}$ for $24 \mathrm{~h}$. The antibacterial activity was subsequently measured as the diameter of the zone of inhibition (within the hole diameter, $\mathrm{mm})$.

\section{RESULTS AND DISCUSSION}

Single-factor experiments: The results for the four studied parameters are shown in Figs. 1 to 4 . The recorded antibacterial diameter for each trial was the average of three parallel measurements. The data were expressed as the mean \pm standard deviation (SD).

Influence of ethanol concentration on antibacterial diameter: The ethanol concentration was set at 20,40, 60 and $80 \%$ to determine the effect of the solvent concentrations on the antibacterial diameter. The solvent-to-solid ratio was $15 \mathrm{~mL} / \mathrm{g}$, the extraction temperature was $55^{\circ} \mathrm{C}$ and the extraction time was $45 \mathrm{~min}$. The antibacterial diameter was increased as the ethanol concentration increased to $60 \%$, before the diameter dropped at solvent concentrations from 60 to $80 \%$ (Fig. 1).

Influence of the solvent-to-solid ratio on antibacterial diameter: The solvent-to-solid ratio was originally not constant during the extraction stages. This ratio was set at 10, 15, 20 and $25 \mathrm{~mL} / \mathrm{g}$ to determine its influence on the antibacterial diameter. The ethanol concentration was $60 \%$, extraction temperature was $55^{\circ} \mathrm{C}$ and extraction time was $45 \mathrm{~min}$. The

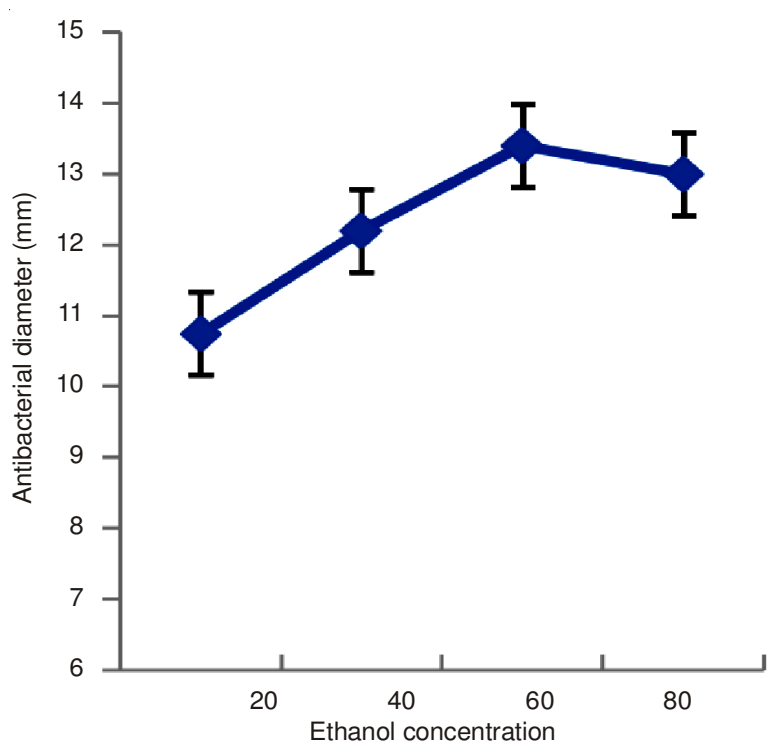

Fig. 1. Influence of ethanol concentration on antibacterial diameter

antibacterial diameter was highest at a solvent-to-solid ratio of $20 \mathrm{~mL} / \mathrm{g}$ (Fig. 2).

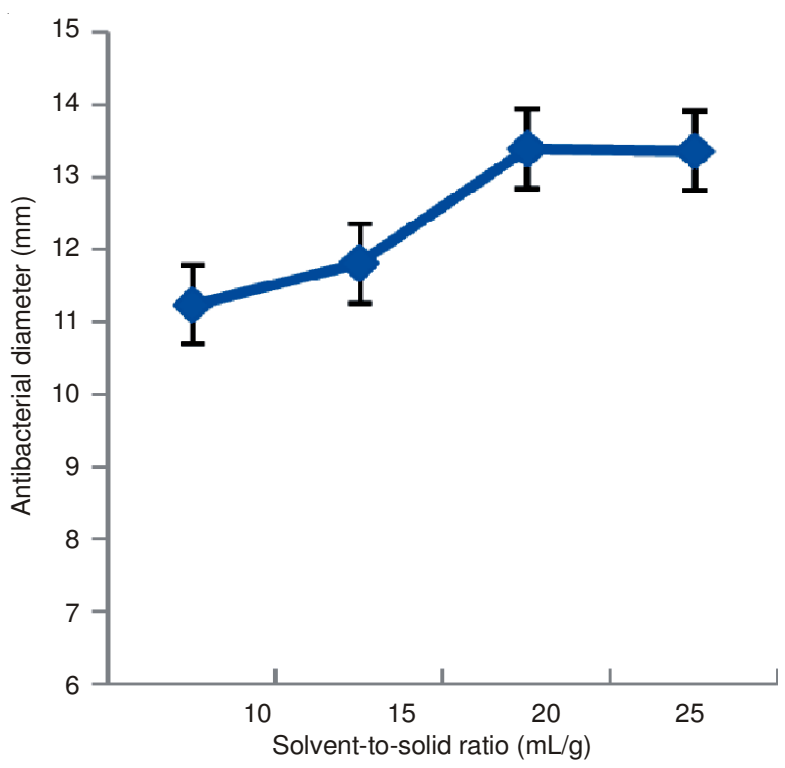

Fig. 2. Influence of solvent-to-solid ratio on antibacterial diameter

Influence of extraction temperature on antibacterial diameter: To determine the effect of extraction temperature on antibacterial diameter, the temperature was set at 35,45 , 55 and $65^{\circ} \mathrm{C}$. The ethanol concentration was $60 \%$, the solvent to solid ratio was $20 \mathrm{~mL} / \mathrm{g}$ and the extraction time was 45 min. The peak antibacterial diameter was obtained at $55^{\circ} \mathrm{C}$ (Fig. 3). This phenomenon could be due to the thermal instability of the antibacterial compounds ${ }^{20}$.

Influence of extraction time on antibacterial diameter: The extraction time is an important factor that determines antibacterial activity. For this experiment, the duration of extraction was set at 30, 45, 60 and $75 \mathrm{~min}$. The overall highest antibacterial diameter was observed with the following conditions: an ethanol concentration of $60 \%$, a solvent-tosolid ratio of $20 \mathrm{~mL} / \mathrm{g}$, an extraction temperature of $55^{\circ} \mathrm{C}$ and an extraction time of $75 \mathrm{~min}$ (Fig. 4). 


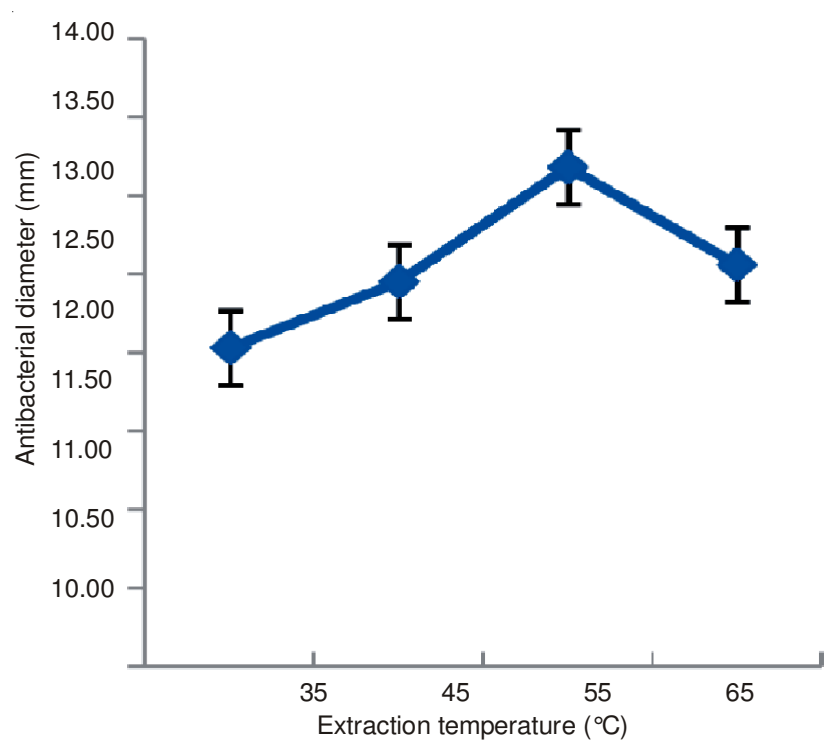

Fig. 3. Influence of extraction temperature on antibacterial diameter

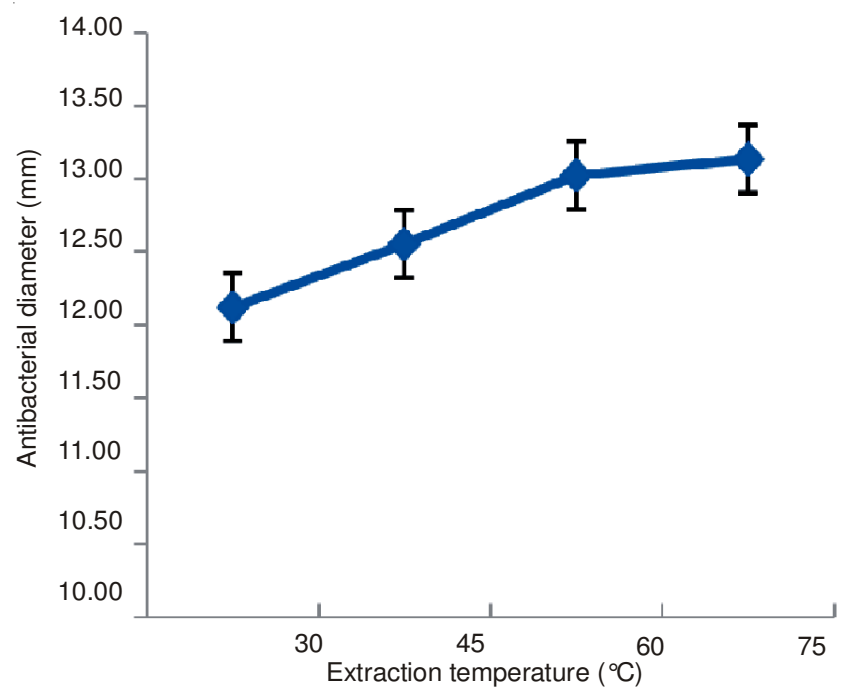

Fig. 4. Influence of extraction time on antibacterial diameter

Response surface methodology optimization: Based on the preliminary results of the single-factor experiment, the four factors chosen for this study were designated as $\mathrm{X}_{1}, \mathrm{X}_{2}, \mathrm{X}_{3}$ and $\mathrm{X}_{4}$. These variables were scored into three levels: "+1," " 0 ," and "- 1 " for the high, intermediate and low values, respectively (Table-1). A total of 27 experiments were conducted using the Box-Behnken design. The experimental conditions and antibacterial diameters (with the blank value subtracted) are summarized in Table- 2 .

Model equation for this four-factor system is:

$$
\begin{aligned}
\mathrm{Y} & =12.92333+1.229167 \mathrm{X}_{1}+0.260833 \mathrm{X}_{2} \\
& +0.08 \mathrm{X}_{3}-0.078333 \mathrm{X}_{4}-1.172917 \mathrm{X}_{1}^{2} \\
& +0.075 \mathrm{X}_{1} \mathrm{X}_{2}+0.1 \mathrm{X}_{1} \mathrm{X}_{3}-0.0825 \mathrm{X}_{1} \mathrm{X}_{4} \\
- & 0.032917 \mathrm{X}_{2}^{2}+0.01 \mathrm{X}_{2} \mathrm{X}_{3}+0.2675 \mathrm{X}_{2} \mathrm{X}_{4} \\
- & 0.164167 \mathrm{X}_{3}^{2}-0.215 \mathrm{X}_{3} \mathrm{X}_{4}-0.566667 \mathrm{X}_{4}^{2}
\end{aligned}
$$

\begin{tabular}{|c|c|c|c|c|c|}
\hline \multicolumn{6}{|c|}{$\begin{array}{c}\text { TABLE-2 } \\
\text { EXPERIMENTAL PARAMETERS OF THE MODEL AND Y } \\
\text { RESPONSE FOR TESTS: ANTIBACTERIAL DIAMETER (Y) }\end{array}$} \\
\hline $\begin{array}{l}\text { Experiment } \\
\text { Number }\end{array}$ & $\begin{array}{c}\mathrm{X}_{1} \\
(\%, \mathrm{v} / \mathrm{v})\end{array}$ & $\mathrm{X}_{2}(\mathrm{~mL} / \mathrm{g})$ & $\mathrm{X}_{3}\left({ }^{\circ} \mathrm{C}\right)$ & $\mathrm{X}_{4}(\mathrm{~min})$ & $\mathrm{Y}(\mathrm{mm})$ \\
\hline 1 & 20 & 10 & 50 & 52.5 & 10.47 \\
\hline 2 & 20 & 25 & 50 & 52.5 & 10.20 \\
\hline 3 & 80 & 10 & 50 & 52.5 & 12.80 \\
\hline 4 & 80 & 25 & 50 & 52.5 & 12.83 \\
\hline 5 & 50 & 17.5 & 35 & 30 & 12.07 \\
\hline 6 & 50 & 17.5 & 35 & 75 & 11.73 \\
\hline 7 & 50 & 17.5 & 65 & 30 & 12.80 \\
\hline 8 & 50 & 17.5 & 65 & 75 & 11.60 \\
\hline 9 & 20 & 17.5 & 50 & 30 & 10.07 \\
\hline 10 & 20 & 17.5 & 50 & 75 & 10.40 \\
\hline 11 & 80 & 17.5 & 50 & 30 & 12.33 \\
\hline 12 & 80 & 17.5 & 50 & 75 & 12.33 \\
\hline 13 & 50 & 25 & 35 & 52.5 & 12.67 \\
\hline 14 & 50 & 25 & 65 & 52.5 & 12.43 \\
\hline 15 & 50 & 10 & 35 & 52.5 & 13.20 \\
\hline 16 & 50 & 10 & 65 & 52.5 & 13.00 \\
\hline 17 & 20 & 17.5 & 35 & 52.5 & 10.13 \\
\hline 18 & 20 & 17.5 & 65 & 52.5 & 10.33 \\
\hline 19 & 80 & 17.5 & 35 & 52.5 & 12.73 \\
\hline 20 & 80 & 17.5 & 65 & 52.5 & 13.33 \\
\hline 21 & 50 & 25 & 50 & 30 & 12.00 \\
\hline 22 & 50 & 25 & 50 & 75 & 11.60 \\
\hline 23 & 50 & 10 & 50 & 30 & 12.60 \\
\hline 24 & 50 & 10 & 50 & 75 & 13.27 \\
\hline 25 & 50 & 17.5 & 50 & 52.5 & 13.13 \\
\hline 26 & 50 & 17.5 & 50 & 52.5 & 12.97 \\
\hline 27 & 50 & 17.5 & 50 & 52.5 & 12.67 \\
\hline
\end{tabular}

where $X_{1}, X_{2}, X_{3}$ and $X_{4}$ are the coded values of the ethanol concentration, solvent-to-solid ratio, extraction temperature and extraction time, respectively. $\mathrm{Y}$ is the antibacterial diameter.

\begin{tabular}{lcccc} 
TABLE-1 & & \\
BOX-BEHNKEN DESIGN \\
\multicolumn{4}{c}{ (EXTRACTION PROCEDURE PARAMETERS) } \\
\hline \multicolumn{1}{c}{ Independent parameters } & $\begin{array}{c}\text { Symbols of the } \\
\text { parameters }\end{array}$ & -1 & 0 & 1 \\
\hline Ethanol concentration $(\%, \mathrm{v} / \mathrm{v})$ & $\mathrm{X}_{1}$ & 20 & 50 & 80 \\
Ratio of solvent/solid $(\mathrm{mL} / \mathrm{g})$ & $\mathrm{X}_{2}$ & 25 & 17.5 & 10 \\
Extraction temperature $\left({ }^{\circ} \mathrm{C}\right)$ & $\mathrm{X}_{3}$ & 35 & 50 & 65 \\
Extraction time $(\mathrm{min})$ & $\mathrm{X}_{4}$ & 30 & 52.5 & 75 \\
\hline
\end{tabular}

The quadratic model indicated that the linear variables $\mathrm{X}_{1}, \mathrm{X}_{2}$ and $\mathrm{X}_{3}$, as well as the two-variable interactions $\mathrm{X}_{1} \mathrm{X}_{2}$, $\mathrm{X}_{1} \mathrm{X}_{3}, \mathrm{X}_{2} \mathrm{X}_{3}$ and $\mathrm{X}_{2} \mathrm{X}_{4}$ showed positive associations with the antibacterial compounds from Amomum tsao-ko fruit. However, the linear variable $\mathrm{X}_{4}$, the quadratic variables $\mathrm{X}_{1}^{2}, \mathrm{X}_{2}^{2}$, $\mathrm{X}_{3}^{2}$ and $\mathrm{X}_{4}^{2}$ and the two-variable interactions $\mathrm{X}_{1} \mathrm{X}_{4}$ and $\mathrm{X}_{3} \mathrm{X}_{4}$ displayed negative effects.

The statistical significance of the regression equation was determined using the $\mathrm{F}$ test and analysis of variance (ANOVA) was likewise performed (Table-3). The values of $\mathrm{R}^{2}, \mathrm{~F}$ and $\mathrm{P}$ were used to check the significance of each coefficient and indicate the interaction strength of each parameter. The regression model could fit well to the response values when the generated $R^{2}$ was high and $P$ was small ${ }^{21}$. The $R^{2}$ of 0.9260 represented the extraction efficiency. This value implied that $92.60 \%$ of the sample variation could be attributed to the independent variables and only $7.4 \%$ of the total variations were not accounted for by the model (Table- 3 ). The values of $\mathrm{F}(11.1422)$ and $\mathrm{P}(0.0001)$ were less than 0.05 , thereby implying that the model was significant. 
TABLE-3

SUMMARY OF ANOVA RESULTS FOR DATA IN TABLE 2

\begin{tabular}{|c|c|c|c|c|c|}
\hline Source & DF & SS & MS & $\mathrm{F}$ & $\operatorname{Pr}>F$ \\
\hline$\overline{X_{1}}$ & 1 & 18.1302 & 18.1302 & 99.3848 & 0.0001 \\
\hline $\mathrm{X}_{2}$ & 1 & 0.8164 & 0.8164 & 4.4753 & 0.0560 \\
\hline $\mathrm{X}_{3}$ & 1 & 0.0768 & 0.0768 & 0.4210 & 0.5287 \\
\hline $\mathrm{X}_{4}$ & 1 & 0.0736 & 0.0736 & 0.4036 & 0.5371 \\
\hline $\mathrm{X}_{1} \times \mathrm{X}_{1}$ & 1 & 7.3372 & 7.3372 & 40.2208 & 0.0001 \\
\hline $\mathrm{X}_{1} \times \mathrm{X}_{2}$ & 1 & 0.0225 & 0.0225 & 0.1233 & 0.7315 \\
\hline $\mathrm{X}_{1} \times \mathrm{X}_{3}$ & 1 & 0.0400 & 0.0400 & 0.2193 & 0.6480 \\
\hline $\mathrm{X}_{1} \times \mathrm{X}_{4}$ & 1 & 0.0272 & 0.0272 & 0.1492 & 0.7060 \\
\hline $\mathrm{X}_{2} \times \mathrm{X}_{2}$ & 1 & 0.0058 & 0.0058 & 0.0317 & 0.8617 \\
\hline $\mathrm{X}_{2} \times \mathrm{X}_{3}$ & 1 & 0.0004 & 0.0004 & 0.0022 & 0.9634 \\
\hline $\mathrm{X}_{2} \times \mathrm{X}_{4}$ & 1 & 0.2862 & 0.2862 & 1.5690 & 0.2342 \\
\hline $\mathrm{X}_{3} \times \mathrm{X}_{3}$ & 1 & 0.1437 & 0.1437 & 0.7879 & 0.3922 \\
\hline $\mathrm{X}_{3} \times \mathrm{X}_{4}$ & 1 & 0.1849 & 0.1849 & 1.0136 & 0.3339 \\
\hline $\mathrm{X}_{4} \times \mathrm{X}_{4}$ & 1 & 1.7126 & 1.7126 & 9.3880 & 0.0098 \\
\hline Model & 14 & 28.4564 & 2.0326 & 11.1422 & 0.0001 \\
\hline (Linear) & 4 & 19.0971 & 4.7743 & 26.1712 & 0.0001 \\
\hline (Quadratic) & 4 & 8.7981 & 2.1995 & 12.0572 & 0.0004 \\
\hline (Cross Product) & 6 & 0.5613 & 0.0935 & 0.5128 & 0.7879 \\
\hline Error & 12 & 2.1891 & 0.1824 & & \\
\hline (Lack of fit) & 10 & 2.0800 & 0.2080 & 3.8142 & 0.2255 \\
\hline (Pure error) & 2 & 0.1091 & 0.0545 & & \\
\hline Total & 26 & 30.6455 & & & \\
\hline
\end{tabular}

ANOVA showed the significant differences among all the sources of variation (Table-3). The quadratic variables $\mathrm{X}_{1}{ }^{2}$ and $\mathrm{X}_{4}^{2}$, as well as the linear variable $\mathrm{X}_{1}$, were highly significant at $\mathrm{P}<0.05$. The linear variable $\mathrm{X}_{2}$ had significant influence $(\mathrm{P}<0.1)$ on the extraction of antibacterial compounds from Amomum tsao-ko fruit. By contrast, the linear variables $\mathrm{X}_{3}$ and $\mathrm{X}_{4}$, the quadratic variables $\mathrm{X}_{2}{ }^{2}$ and $\mathrm{X}_{3}{ }^{2}$ and the two-variable interactions $\mathrm{X}_{1} \mathrm{X}_{2}, \mathrm{X}_{1} \mathrm{X}_{3}, \mathrm{X}_{1} \mathrm{X}_{4}, \mathrm{X}_{2} \mathrm{X}_{3}, \mathrm{X}_{2} \mathrm{X}_{4}$ and $\mathrm{X}_{3} \mathrm{X}_{4}$ had no significant influence $(\mathrm{P}>0.1)$ on the extraction efficiency.

As shown in Table-3, the Model, Linear and Quadratic values all had significant influences on the extraction efficiency $(\mathrm{P}<0.05)$, unlike the Cross Product value $(\mathrm{P}>0.05)$. The Lack of fit value $(\mathrm{P}>0.05)$ implied that the quadratic polynomial regression model was suitable.

These results showed that the ethanol concentration and of the solvent-to-solid ratio were important variances when extracting antibacterial compounds from Amomum tsao-ko fruits by UMAE, whereas the extraction temperature and extraction time were not significant.

The numerical optimization results showed that the maximum antibacterial diameter was obtained with an ethanol concentration of $65 \%$, a solvent-to-solid ratio of $25 \mathrm{~mL} / \mathrm{g}$, an extraction temperature of $57.5^{\circ} \mathrm{C}$ and an extraction time of $52.5 \mathrm{~min}$. The highest antibacterial diameter of $14.20 \mathrm{~mm}$ obtained from the optimized conditions in this study was verified to be better than that of the other extraction conditions.

\section{Conclusion}

Compounds from Amomum tsao-ko fruit extracted under the optimal conditions exhibited higher antibacterial activity against $E$. coli. The optimized conditions included an ethanol concentration of $65 \%$, a solvent-to-solid ratio of $25 \mathrm{~mL} / \mathrm{g}$, an extraction temperature of $57.5^{\circ} \mathrm{C}$ and an extraction time of $52.5 \mathrm{~min}$. Ultrasonic- and microwave-assisted extraction was demonstrated to have higher extraction efficiency. Moreover, the use of RSM for the extraction of antibacterial compounds effectively determined the best combination of parameters. These processes allowed for the more efficient and faster extraction of antibacterial substances.

The present study also demonstrates a comparable antibacterial potential of the Amomum tsao-ko fruit extract. The possible antibacterial compounds may be saponins, flavanoids, phenols and alkaloids ${ }^{22,23}$. The feasible antibacterial mechanism may be by damaging the structure, function and permeability of $E$. $\operatorname{coli}^{24}$. Further studies in this area still require more effort.

\section{ACKNOWLEDGEMENTS}

This research was supported by the Natural Science Foundation of Hainan Province, China (312073, 211008).

\section{REFERENCES}

1. T. Zhang and D.F. Chen, J. Ethnopharmacol., 117, 351 (2008).

2. T. Martin, H. Kikuzaki, M. Hisamoto and N. Nakatani, J. Am. Oil Chem. Soc., 77, 667 (2000).

3. S.S. Moon, J.Y. Lee and S.C. Cho, J. Nat. Prod., 67, 889 (2004).

4. X. Yang, P. Küenzi, I. Plitzko, O. Potterat and M. Hamburger, Planta Med., 75, 543 (2009).

5. S.S. Moon, S.C. Cho and J.Y. Lee, Bull. Korean Chem. Soc., 26, 447 (2005).

6. Y. Yang, Y. Yue, Y. Runwei and Z. Guolin, Bioresour. Technol., 101, 4205 (2010).

7. K. Lee, S. Kim, S. Sung and Y. Kim, Planta Med., 74, 867 (2008).

8. C. Starkenmann, F. Mayenzet, R. Brauchli, L. Wunsche and C. Vial, J. Agric. Food Chem., 55, 10902 (2007).

9. L. Yu, N. Shirai, H. Suzuki, T. Hosono, Y. Nakajima, M. Kajiwara and K. Takatori, J. Nutr. Sci. Vitaminol. (Tokyo), 54, 378 (2008).

10. H.Y. Qiu, X.L. Liu, W.X. Chen, L.Y. Wu and Q. Wang, Sci. Technol. Food Ind., 104, 11 (2012).

11. I. Karabegovic, M. Nikolova, D. Velickovic, S. Stojicevic, V. Veljkovic and M. Lazic, Chin. J. Chem. Eng., 50, 194 (2011).

12. G. Zhang, M. Hu, L. He, P. Fu, L. Wang and J. Zhou, Food Bioprod. Process., 91, 158 (2013).

13. J.H. Xie, M.Y. Shen, M.Y. Xie, S.P. Nie, Y. Chen, C. Li, D.F. Huang and Y.X. Wang, Carbohydr. Polym., 89, 177 (2012).

14. M. Bendahou, A. Muselli, M. Grignon-Dubois, M. Benyoucef, J. Desjobert, A. Bernardini and J. Costa, Food Chem., 106, 132 (2008).

15. M. Plaza, S. Santoyo, L. Jaime, B. Avalo, A. Cifuentes, G. Reglero, G. García-Blairsy Reina, F.J. Señoráns and E. Ibáñez, LWT-Food Sci. Technol., 46, 245 (2012).

16. E.M.Z. Michielin, A.A. Salvador, C.A.S. Riehl, A. Smânia Jr., E.F.A. Smania and S.R.S. Ferreira, Bioresour. Technol., 100, 6615 (2009).

17. Y.Y. Chen, X.H. Gu, S.Q. Huang, J.W. Li, X. Wang and J. Tang, Int. J. Biol. Macromol., 46, 429 (2010).

18. Z. Lianfu and L. Zelong, Ultrason. Sonochem., 15, 731 (2008).

19. B.G. Rao, P.U. Rao, E.S. Rao, T.M. Rao and V.S. Praneeth. D, Asian Pac. J. Trop. Biomed., 2, 818 (2012).

20. H.P.S. Chauhan and N.M. Shaik, J. Inorg. Biochem., 99, 538 (2005).

21. C. Liyana-Pathirana and F. Shahidi, Food Chem., 93, 47 (2005).

22. R.N. Yadava and J. Jharbade, Fitoterapia, 79, 245 (2008).

23. A.S. Sufian, K. Ramasamy, N. Ahmat, Z.A. Zakaria and M.M. Yusof, J. Ethnopharmacol., 146, 198 (2013).

24. X.F. Li, X.Q. Feng, S. Yang, G.Q. Fu, T.P. Wang and Z.X. Su, Carbohydr. Polym., 79, 493 (2010). 